\title{
Low carbohydrate meals or a small dose of insulin normalises one-hour blood glucose in a woman with normal glucose tolerance and elevated one-hour postload glucose: a case report
}

\author{
Sally A Vindedzis,' Beryl Marsh,' Jill L Sherriff,' \\ Satvinder S Dhaliwal' ${ }^{2}$ Kim G Stanton'
}

\section{Introduction}

Diabetes is diagnosed by 2-hour BGL $\geq 11.1 \mathrm{mmol} / \mathrm{L}$ on OGTT, fasting BGL $\geq 7.0 \mathrm{mmol} / \mathrm{L}$ or $\mathrm{HbA}_{1 \mathrm{C}} \geq 6.5 \% .{ }^{1} \mathrm{IFG}$ and IGT are similarly diagnosed by elevated fasting and 2-hour BGLs. ${ }^{1}$ Although 1-hour BGL is routinely measured, results are classified as NGT if fasting and 2-hour levels are normal, irrespective of elevation at 1 hour. It has, however, been shown that 1-hour postload BGL is a strong predictor of future risk for type 2 diabetes and vascular disease, even in those with NGT.2,3 Additionally Meisinger et al. identified 1-hour postload glycaemia as a long-term predictor for all-cause mortality in men without diabetes. ${ }^{4}$ There is no normal range for 1-hour glucose, but $\geq 8.6 \mathrm{mmol} / \mathrm{L}$ has been identified as a cut-off marking increased cardiovascular and diabetes risk. ${ }^{2,3,5}$ It has been suggested that recognition and management of those with NGT and 1-hour glucose $\geq 8.6 \mathrm{mmol} / \mathrm{L}$ may reduce incidence of diabetes and vascular events. ${ }^{3,4}$

This case report has been approved by Curtin University Human Research Ethics Committee, an institutional ethics committee, and a consent form has been signed.

\section{Case report}

A.J., a 59-year-old Caucasian woman, had noted elevated BGLs soon after eating for about 10 years. In 2005 her OGTT showed a 1-hour level of $8.0 \mathrm{mmol} / \mathrm{L}$ with normal fasting and 2-hour levels $(4.5$ and $4.7 \mathrm{mmol} / \mathrm{L}$ respectively). When repeated in 2008 her BGL reached $11.7 \mathrm{mmol} / \mathrm{L}$ at 1 hour and was down to $7.2 \mathrm{mmol} / \mathrm{L}$ by 2 hours. Concurrent assessment of serum insulin showed a 1-hour level of $73 \mathrm{mU} / \mathrm{L}$, remaining elevated at 2 hours (27 mU/L). SBGM had shown normal fasting levels on most occasions, but had risen to $6-8 \mathrm{mmol} / \mathrm{L}$ with acute illness. One-hour postprandial levels were often above $10 \mathrm{mmol} / \mathrm{L}$ when she ate a carbohydratecontaining meal. Apart from postprandial hyperglycaemia A.J. had no other vascular risk factors and did not fit criteria for metabolic syndrome. She had a raised
Abbreviations:
BGL blood glucose level
$\mathrm{BMI}$ body mass index
$\mathrm{HbA}_{I C}$ glycated haemoglobin $\mathrm{A}_{I C}$
IFG impaired fasting glucose
IGT impaired glucose tolerance
NGT normal glucose tolerance
OGTT oral glucose tolerance test
SBGM self blood glucose monitoring

LDL which responded to Lipitor but no evidence of a metabolic dyslipidaemia. Her blood pressure was 100/70. Until 2008 A.J. had noted increased postprandial hunger resulting in slow weight gain, although her BMI remained well within the normal range (2001, 60 $\mathrm{kg}, 20.5 ; 2008,64.3 \mathrm{~kg}, 22.3)$.

Repeat SBGM over four standard meals showed a 1-hour postload rise significantly associated with meal carbohydrate quantity $(\mathrm{p}=0.024)$ but not glycaemic index $(\mathrm{p}=0.51)$ (Table 1). Mean 2-hour postload drop was $5.6 \pm 2.6 \mathrm{mmol} / \mathrm{L}$.

A.J. commenced sitagliptin but after 4 months of treatment felt there was insufficient change in her 1-hour levels to warrant continuing. She elected to limit carbohydrate intake in most meals (5-10 g/meal) and use a small dose of short-acting insulin $\left(1 / 2-1 \frac{1}{2}\right.$ units) before those meals when she elected to have more carbohydrate.

'Department of Endocrinology and Diabetes, Royal Perth Hospital, Perth, WA, Australia

${ }^{2}$ School of Public Health, Curtin Health Innovation Research Institute, Curtin University, Bentley, WA, Australia

\section{Corresponding author:}

Sally Vindedzis, Department of Endocrinology and Diabetes, Royal Perth Hospital, GPO Box X2213, Perth, Western Australia, 600I, Australia. Email: sally.vindedzis@postgrad.curtin.edu.au 
Table I. Standard meals: content, carbohydrate load, glycaemic index and mean I-hour postload rise in blood glucose.

\begin{tabular}{|c|c|c|c|c|}
\hline Stndard meal & Foods & $\mathrm{CHO}(\mathrm{g})$ & GI & I-h BGL mmol/L \\
\hline Meal I & $\begin{array}{l}\text { I } 1 / 2 \text { slice mixed grain toast } \\
\text { I dsp dairy soft } \\
\text { I dsp apricot jam } \\
70 \mathrm{~mL} \text { orange juice } \\
\text { Coffee }+50 \mathrm{~mL} \text { soy milk }\end{array}$ & 41.8 & 47.8 & $8.2 \pm 1.8$ \\
\hline Meal 2 & $\begin{array}{l}\text { Long wheat roll } \\
\text { Mixed green salad } \\
45 \mathrm{~g} \text { cheese }\end{array}$ & 28.2 & 59 & $7.7 \pm 0.9$ \\
\hline Meal 3 & $\begin{array}{l}\text { Cannellini vegetable casserole } \\
2 \text { tbsp basmati rice } \\
\text { Green salad } \\
\text { Naan bread - palm sized } \\
80 \mathrm{~mL} \text { dry wine }\end{array}$ & 34.9 & 48.3 & $6.8 \pm 2.9$ \\
\hline Meal 4 & $\begin{array}{l}\text { I mixed grain toast } \\
\text { I dsp dairy soft } \\
2 \text { tsp vegemite } \\
80 \mathrm{~mL} \text { orange juice } \\
1 / 4 \text { apple }\end{array}$ & 25.1 & 46.1 & $3.9 \pm 0.9$ \\
\hline
\end{tabular}

Key: CHO: carbohydrate; dsp: dessert spoon; Gl: glycaemic index; I-h BGL: mean rise blood glucose I-hour postload.

Carbohydrate content from Foodworks 7, Xyris Software (Aust) Pty Ltd 2012, QId, Australia.

Gl from Atkinson FS et al. ${ }^{6}$

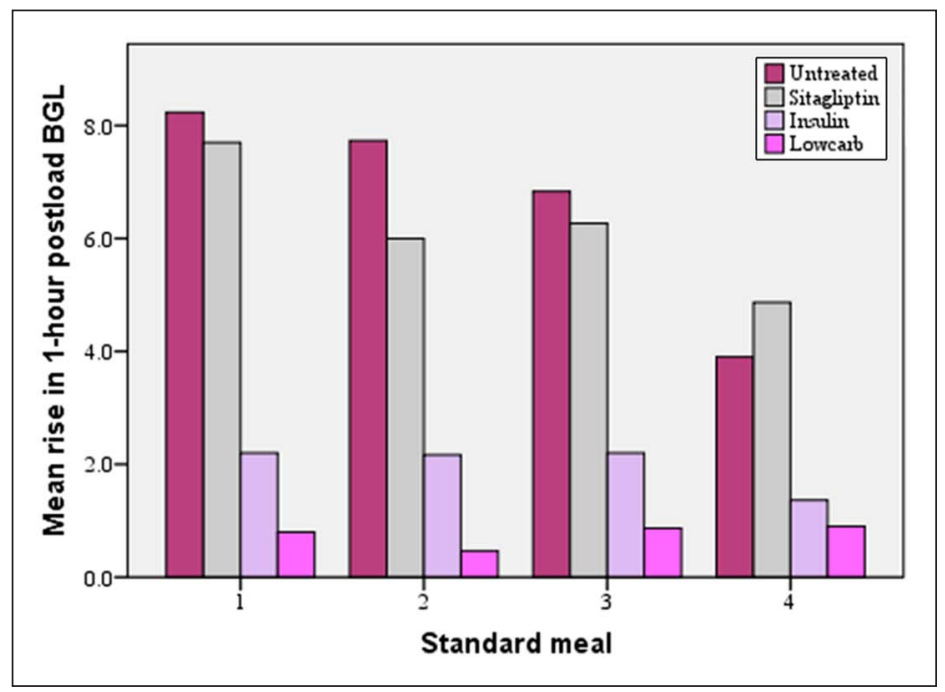

Figure I. Mean rise in I-hour postload blood glucose level (BGL) following four standard meals.

Mean repeat SBGM results are shown in Figure 1. Repeated measures ANOVA showed a significant difference between 1-hour postload rise for low carbohydrate and insulin-treated meals compared with no treatment or sitagliptin $(\mathrm{p}<0.001)$; there was no significant difference between no treatment and sitagliptin $(p=0.26)$. On her current regime postprandial hunger has diminished with $3.6 \mathrm{~kg}$ weight loss over 4 years.

\section{Discussion}

The significance of elevated postload 1-hour BGL is currently being debated. Whereas a diagnosis of IFG/IGT elicits advice on diabetes risk, diet, exercise and, more recently, metformin, ${ }^{7}$ NGT with 1-hour BGL $\geq 8.6$ $\mathrm{mmol} / \mathrm{L}$ is classified normal and no preventative measures taken, despite evidence that these individuals have 
an atherogenic profile similar to those with IGT $^{5}$ and a similarly increased risk of type 2 diabetes. $^{2}$

We have described a case where two relatively straightforward interventions resulted in normalisation of elevated 1-hour postload BGL. Surprisingly sitagliptin, which has demonstrated positive effects on first phase insulin secretion, ${ }^{8}$ had relatively little effect, although there was a trend to decreased 1-hour BGL with increased carbohydrate load. Our subject therefore chose a combination of mainly low carbohydrate meals combined with a small insulin dose before meals with $>10 \mathrm{~g}$ carbohydrate. One possible pitfall of low carbohydrate diets is increased saturated fat intake, but with proper design, this can be avoided. Such diets generally have good satiety and acceptance, although there is some evidence that adherence decreases over time. ${ }^{9}$ Insulin treatment is more intrusive. A small dose before carbohydrate-containing meals only, minimises the risk of hypoglycaemic episodes, but still entails the necessity of SBGM. Our subject additionally noted that treatment appeared to reduce her postprandial hunger, thus facilitating weight loss. Her insulin profile at OGTT was consistent with Harada's thesis of decreased early phase insulin secretion giving rapid postprandial rise in BGL thus exaggerated second phase insulin response resulting in a rapid fall in BGL to normal levels by 90 minutes. ${ }^{10}$ Her resulting postload drop at 2 hours is consistent with relative hypoglycaemia ${ }^{11}$ and could well result in hunger and putative weight gain.

Cubeddu et al. showed that $8.3 \%$ of those with NGT have1-hour $\mathrm{BGL} \geq 8.6 \mathrm{mmol} / \mathrm{L},{ }^{3}$ so this condition is not unusual, but treatment of it is. This case demonstrates a practical intervention effective over 4 years. A case series is now needed to further investigate this.

\section{Funding}

This research received no specific grant from any funding agency in the public, commercial, or not-for-profit sectors.

\section{Declaration of conflicting interests}

The authors have no conflicts of interest to declare

\section{References}

1. American Diabetes Association. Diagnosis and classification of diabetes mellitus. Diabetes Care 2012; 35(supplement 1): S64-71.

2. Abdul-Ghani MA, Abdul-Ghani T, Ali N, DeFronzo RA. One-hour plasma glucose concentration and the metabolic syndrome identify subjects at high risk for future type 2 diabetes. Diabetes Care 2008; 31: 1650-55.

3. Cubeddu LX, Hoffmann IS. One-hour postload plasma glucose levels, a predictor of additional risk for diabetes: prevalence, mechanisms, and associated cardiovascular and metabolic risk factors in Hispanics. Metab Syndr Relat Disord 2010; 8: 395-402.

4. Meisinger C, Wölke G, Brasche S et al. Postload plasma glucose and 30-year mortality among nondiabetic middle-aged men from the general population: The ERFORT Study. Ann Epidemiol 2006; 16: 534-9.

5. Succurro E, Marini MA, Arturi F et al. Elevated one-hour post-load plasma glucose levels identifies subjects with normal glucose tolerance but early carotid atherosclerosis. Atherosclerosis 2009; 207: 245-9.

6. Atkinson FS, Foster-Powell K, Brand-Miller JC. International Tables of Glycemic Index and Glycemic Load Values: 2008. Diabetes Care 2008; 31: 2281-3.

7. Nathan DM, Davidson MB, DeFronzo RA et al. Impaired fasting glucose and impaired glucose tolerance. Diabetes Care 2007; 30 :753-9.

8. Aaboe K, Knop FK, Vilsboll T et al. Twelve weeks treatment with the DPP-4 inhibitor, sitagliptin, prevents degradation of peptide YY and improves glucose and non-glucose induced insulin secretion in patients with type 2 diabetes mellitus. Diabetes Obes Metab 2010; 12: 323-33.

9. Berkow S, Barnard N, Eckart J, Katcher H. Four therapeutic diets: adherence and acceptability. Can J Diet Pract Res 2010; 71: 199-204.

10. Harada N, Fukushima M, Toyoda K et al. Factors responsible for elevation of 1-h postchallenge plasma glucose levels in Japanese men. Diabetes Res Clin Pract 2008; 81: 284-9.

11. Cryer PE, Axelrod L, Grossman AB et al. Evaluation and management of adult hypoglycemic disorders: an Endocrine Society Clinical Practice Guideline. J Clin Endocrinol Metab 2009; 94: 709-28. 